\title{
Disentangling core functions of operational resilience: A critical review of extant literature
}

\author{
Seyoum Eshetu Birkie* \\ Department of Management, Economics and Industrial Engineering, \\ Politecnico di Milano, \\ KTH Royal Institute of Technology, \\ Piazza Leonardo Da Vinci, 32, 20133 Milan, Italy \\ E-mail: seyoumeshetu.birkie@polimi.it \\ *Corresponding author \\ Paolo Trucco \\ Department of Management, Economics and Industrial Engineering, \\ Politecnico di Milano, \\ Piazza Leonardo Da Vinci, 32, 20133 Milan, Italy \\ E-mail: paolo.trucco@polimi.it

\section{Matti Kaulio} \\ Department of Industrial Economics and Management, \\ KTH Royal Institute of Technology, \\ SE-100 44, Stockholm, Sweden \\ E-mail: matti.kaulio@indek.kth.se
}

\begin{abstract}
This study identifies and systematically reviews the literature on resilience in management research in order to characterise operational resilience. We argue that operational resilience provides an integrative view on different resilience perspectives in business (supply chain, business continuity, infrastructure, organisational, strategic). Using the resource-based view and particularly dynamic capabilities perspective as theoretical lenses, operational resilience is discussed in relation to the core business processes of an enterprise. Five core functions (sense, build, reconfigure, re-enhance, sustain) are identified from literature and discussed taking into account desired and undesired consequences of uncertainties. Moreover, operational resilience is operationalised using routines pertaining to the identified core functions. The proposed operational resilience core functions are further scrutinised using two case examples. Future research is suggested to validate the identified core functions and to use them for empirical analysis, including investigation of relationships with operations management paradigms such as lean thinking.
\end{abstract}

Keywords: operational resilience; operational risk management; uncertainty; supply chain management; business continuity; dynamic capabilities; literature review

\section{Introduction}

Unexpected incidents have significant implications on businesses. Operations halt or get delayed, customers become dissatisfied, and subsequently wealth creation is severely affected. Significant resources are committed to offset such unwanted consequences, but they seldom meet with success. Reactive approaches are expensive and largely unsuccessful. Proactive approaches based merely on the identification and analysis of risks require investments with low returns. Besides, they are limited to addressing uncertainties for which historical data are available. It is therefore of increasing interest to investigate what makes firms operationally more capable of fulfilling their business targets in the face of unexpected events.

As a concept, resilience is a popular term that has been used in different knowledge domains such as ecological studies (Holling, 1996), psychology (Coutu, 2002), engineering (Hollnagel, 2006), and supply chain management (Sheffi and Rice, 2005). The use of the term resilience in scientific publications within management research increased post 9/11 (Christopher and Peck, 2004). In addition, a large number of articles have been published in the field after the 2008 global financial crisis (Park et al., 2013).

In the management research literature, authors have viewed resilience from different perspectives. The term had been borrowed from other disciplines, as mentioned. A large number of normative and descriptive definitions have developed as a result. Without any explicit definition of what resilience is, an implicit understanding of the concept is used in some literature, which has left as much room for confusion over meaning as it has fostered multidisciplinary communication. As the use of the term has increased and spread into new disciplines, the meaning of the concept has changed (Brand and Jax, 2007). An interesting dilemma is 
then how to reconcile the multifaceted nature of resilience reflected in the different perspectives but not fully covered by a single one of these perspectives when used in management research.

The aim of this study is to identify core functions based on critical analysis of relevant literature to characterise operational resilience concept. In doing so, we intend to clarify the relationships between operational and supply chain resilience, as well as other related concepts. To achieve this aim, we have reviewed publications that have contributed to advancing our understanding of resilience in management. We believe this study paves the way for a practical implementation and measurement of operational resilience, something that has consistently been called for (Bhamra et al., 2011).

The paper is organized as follows. Section 2 presents a brief overview of resilience and the theoretical frame. In section 3 we describe the methodology used in this critical review. Section 4 discusses the critical analysis including identification of core operational resilience functions. Two short cases are presented and discussed in section 5 to examine identified core functions. Our concluding remarks in section 6 highlight operational resilience issues beyond definition and conceptualisation for future research.

\section{Theoretical overview}

\subsection{General characteristics of resilience}

The conceptualisation and definitions of resilience used in several fields including management research appear to follow some pioneering contributors. Such contributors include Holling (1973) who characterises resilience as the ability to persist and to absorb disturbances. Hamel and Välikangas (2003) take Holling's idea in order to conceptualise the strategic resilience of organisations as the ability to dynamically re-invent strategies under changing circumstances. Carpenter et al. (2001) view resilience as measured by the "amount of disturbance" that the system can tolerate without losing its proper function. Supply chain resilience contributors discuss mechanisms that make enterprises resilient, rather than depending on mere luck when they encounter disruptions (Caniato et al., 2011; Christopher and Peck, 2004; Sheffi and Rice, 2005). Cumming has also been a significant contributor to the discussion of risk assessment as a scientific method in early 80's, and later to the discussions on the empirical measurement of resilience (Aven, 2012; Cumming et al., 2005).

To guide our discussion of resilience characteristics, in the upcoming sub-sections we use the resilience definitions of some prominent writers. Appendix A provides some resilience definitions proposed by different scholars.

\subsubsection{Uncertainty and dynamism in business circumstances}

In a broad sense, definitions and conceptual characterisations of resilience in different domains provide a minimum set of grounding elements that are applicable to business enterprises. These elements are:

- Unanticipated changes (disorders) occur following some triggering event or series of events which induce change of state in entities. In our specific case, an entity refers to a business enterprise (Christopher and Peck, 2004; Sheffi, 2007), but it also could refer to a physical or ecological system (Holling, 1973).

- The entities are assumed to possess some internal capabilities for "coping with or adapting to the changes” and returning to a previous or a better state of equilibrium (Christopher and Peck, 2004; Holling, 1973).

- Capabilities are shaped by interaction with the environment in specific circumstances (Välikangas, 2010).

Although the above mentioned characteristics present the minimum set of grounding elements, there are differences regarding, for instance, the origin of the cause. In ecosystem studies and engineering, changes are considered to result from external causes only. In business environments, however, the sources of change can be internal or external depending on the complex interactions of humans, information and infrastructure "subsystems" that result in variations to normal operations and allow "cause-effect chains" develop throughout core operational processes (Silvestri et al., 2011). For any given enterprise, workers striking or the loss of critical technological assets may be considered to be internal causes of production disruptions. Moreover, what has been recognised as external may become recognised as internal, or vice versa.

\subsubsection{Complexity and difficulty to measure}

Circumstances that cause misalignment between business requirements and operational achievements are diverse and possibly overlapping (Lewis, 2003). Operational capabilities required to re-gain a fit in such conditions accordingly differ, as discussed by Lewis (2003). As such, there is no one-size-fits-all solution to achieve and maintain higher resilience. Approaches to making an enterprise resilient are context dependent. 
Higher complexity and interdependence of systems make it more difficult to exploit and measure resilience (Park et al., 2013).

Many studies on resilience rely on descriptive approaches (Brand and Jax, 2007). Retrospective analysis is used to investigate how some businesses perform better than others when faced with similar adversities. They often use indicative mechanisms and specific actions that depend on prevailing circumstances as well as industry and firm-related variables. Consistent measurement of resilience remains a challenge. The availability of different empirical and analytical studies makes it now possible and important to further investigate normative approaches to conceptualising resilience in business enterprises. For this reason, this study identifies and discusses operational resilience tenets.

\subsection{Different resilience perspectives and the context of operational resilience}

As briefly indicated in the introduction, research on resilience has been developed in multidisciplinary fields. Earlier contributions on what resilience is and how it should be characterised come from at least three different directions: psychology, ecological studies and engineering. Ecological studies postulate that resilience of an ecological system lies in how much change induced by external factors the system can withstand before exhibiting changes in its normal relationships (Holling, 1973). Therefore sustaining this normal relationship measures the resilience of the ecosystem. In physics and engineering, resilience is more often related to how much external pressure a material can withstand without losing its elasticity after the pressure has been relieved (Hollnagel, 2006). Often this perspective is related to safety issues in man-machine systems (Francis and Bekera, 2014). The psychological perspective on resilience discusses how individuals (and groups) cope with circumstances that create emotional and psychological stress (Coutu, 2002).

Later discussions on the resilience of varying complex socio-technical systems have built on these early perspectives. It is not uncommon for publications to refer back to more than one resilience perspective in their conceptual and empirical discussions. For instance, Park et al. (2013) bring in engineering and ecological views of resilience when discussing infrastructure resilience. Some of the papers reviewed in this study have reviewed earlier resilience perspectives. Many definitions of resilience and interactions relating the perspectives can be found in them (e.g., Bhamra et al., 2011; Francis and Bekera, 2014; Ponomarov and Holcomb, 2009). Among these perspectives, the ones that strongly contribute in understanding operational resilience are supply chain resilience, organisational resilience, strategic resilience, infrastructure resilience, and business continuity. We argue that by systematically analysing these resilience perspectives, it is possible to understand and portray the core identity of operational resilience in businesses.

\subsection{Resilience in supply chain operations}

Operational resilience can be viewed from the perspective of supply chain operations in a business enterprise. According to the Supply Chain Council (SCC), all operations carried out at different boundary levels of a supply chain consist of five first level processes: Plan, Source, Make, Deliver and Return (SCC, 2010). Since these operations are not executed in isolated systems, they may possess several vulnerabilities that have the potential to generate uncertainties or may hinder the system from operationally excelling in such cases. Planning is usually subject to forecasting errors, long forecast horizons, and control rigidity. Sourcing can be challenged by single-sourcing, suppliers shared with competitors, or just-in-time delivery (e.g., Sheffi, 2007). Strong coupling of processes, product diversity and unavailability of input challenge the make operation (e.g., Christopher and Peck, 2004). To deliver required goods and services timely, in addition to addressing limitations and interdependencies in logistics infrastructures, the make operation should function properly (Craighead et al., 2007).

Many researchers of supply chain resilience argue that it is vitally important to secure a steady supply of inputs so as to reduce disruption of make operations, which in turn affect deliver (Craighead et al., 2007). While this is true, it may not present the whole picture, because in addition to sourcing there are other possible causes that disrupt the make operation. Having capabilities to mitigate sourcing disruptions does not suffice to make a firm operationally resilient. On the contrary, better operational resilience can be achieved only through a proper evaluation of internal resilience capabilities, the capabilities and limitations of other links in the supply chain, and the different roles played by the enterprise in the (different) supply chains it belongs to. Internal capabilities can leverage competitive advantages as well as benefit other supply chain members (or even members of other indirectly connected supply chains), by, at least, not inducing disruptive events.

Negative or positive changes could be caused by such factors as capacity limitations, quality problems, natural/man-made disasters, supplier default or switching, price/cost changes, order backlogs, anticipatory orders, excess/low inventory, demand changes, promotions. Many of such causes tend to form "cause-effect chains", inducing cascading effects on multiple processes. Some coping mechanisms discussed in the literature are: contingency planning, multi-sourcing, contractual arrangements, visibility across a supply chain, better coordination, spare capacity, decoupling operations, multitasking, agility, standardisation, postponement, revenue management/pricing policy (Carvalho et al., 2011; Melnyk et al., 2010; Pettit et al., 2010; Rice and Caniato, 2003; Sheffi, 2007). Some of such mechanisms may not be addressed by the supply chain roles. That is 
why operational resilience becomes important, and its core functions might not be completely covered by the supply chain view of resilience. The systematic review in the present study sheds new light on this relationship.

\subsection{Dynamic capabilities perspective as theoretical lens}

Different theoretical frames have been used in discussions of resilience in management research. For example, Ponomarov and Holcomb (2009) use the resource-based view (RBV); Ismail et al. (2011) employ the dynamic capabilities perspective of the RBV in their studies. Complex systems and network theories (Cumming et al., 2005; Hearnshaw and Wilson, 2013), high reliability theory (Boin and van Eeten, 2013; Weick and Sutcliffe, 2007), and social capital theory (Johnson et al., 2013) are further examples of theoretical frames used in discussing the resilience concept. In this study we use the dynamic capabilities perspective of RBV as theoretical frame.

In the classical RBV literature, the importance of capabilities possessing distinctive, difficult to imitate tangible assets has not been sufficiently emphasised. Nevertheless, it is the possession of resources as well as the way businesses organise to exploit those resources that creates unique capabilities for volatile circumstances in prevailing business environments (Ambrosini and Bowman, 2009; Teece et al., 1997). Dynamic capabilities perspective is a variant of RBV that considers firms as bundles of heterogeneous and path dependent resources. It recognises that capabilities useful in the future are created or refreshed from existing ones in changing circumstances (Peng et al., 2008; Teece et al., 1997).

Capabilities that are aimed to provide competitive edge in face of changing circumstances are called dynamic capabilities. A dynamic capability is "the firm's ability to integrate, build, and reconfigure internal and external competences to address rapidly changing circumstances” [Teece et al., (1997), p.516]. Dynamic capabilities are not spontaneous actions or ad hoc problem solving. Rather, they are intentional routines that impact on resources, and that are formed from internally consistent bundles of routines that impact on resources (Ambrosini and Bowman, 2009; Peng et al., 2008). Routines can be defined as "regular and predictable behavioural patterns or how work is done” (Peng et al., 2008). Dynamic capabilities are built and embedded in firms and cannot be instantaneously procured from the market place. In accordance with the dynamic capabilities perspective, this paper pursues the argument that resilience can be viewed as a set of dynamic capabilities exploited in line with prevailing circumstances, i.e. threats and opportunities (Teece et al., 1997).

\section{In search of operational resilience core functions: Study methodology}

\subsection{Method of literature search}

We used the following approach when searching the literature. First, important reference publications, resilience definitions and descriptive explanations were identified from general literature on resilience (in the domains of ecological studies, engineering, psychology, sociology, risk management, and other business-related areas). We then performed a search of publications (books, chapters, journal articles) using a logical combination of relevant keywords in topic, abstract and title of the publications (see Appendix B). Web of Knowledge ${ }^{\mathrm{SM}}$ and Scopus ${ }^{\circledR}$ were used in the search, which was limited to publication sources on management, business, risk, and decision science studies.

Next we performed the detail review by scanning abstracts (and full papers when necessary) of publications to short-list the most relevant papers in line with our objectives and scope. Some interesting publications not indexed in the search tools (such as book chapters) were identified from the references of the short-listed papers and were included in the review. A major criterion for inclusion in the detailed review was that the publication had to either state a definition for or clearly describe what enterprise-related resilience is. Some of the publications build mainly on previous contributions by the same authors (i.e., extension of a study, testing previously proposed theory, etc.). We reviewed most of these publications but preferred to cite only the most relevant versions.

\subsection{Method of review}

The result of the short listing for detailed review of the resilience concept in management research consists of 41 publications (35 articles, six books and chapters). Five of the 35 articles are, or have, extensive literature reviews on resilience. This is considered as leverage for our study as it enables us to capture the literature on resilience in broader terms without having to review a large number of publications. Some of the studies that we did not include in our final shortlist are also reflected in these literature review publications. The detail review is used to understand how resilience is conceptualised in management research, and to identify some core issues that can be extended to operational resilience conceptualisation. Based on this, we have identified core functions of operational resilience in business enterprises. 


\section{Discussion}

\subsection{Major research streams on resilience in business contexts}

As mentioned in section 3, we reviewed 41 publications - of which 35 are journal articles - for the investigation of operational resilience core functions. About $50 \%$ of the total of the reviewed literature were published in the years 2011-2013, reflecting the increasing use of the concept in business related studies after the 2008 financial crisis and recent natural disasters that affected many global businesses.

Different perspectives are advanced in business related resilience literature in which operational resilience core functions are reflected, the main ones being 1) supply chain risk and resilience management, 2) organisational resilience, 3) strategic management, 4) business continuity and crisis management, 5) infrastructure resilience, and 6) systems engineering.

The literature on supply chain resilience concentrates on resilience aspects related to velocity, flexibility, visibility and collaboration (Jüttner and Maklan, 2011; Oh and Teo, 2006). The organisational resilience literature is mainly concerned with learning and dynamism in humans as collective decision makers (e.g., Välikangas, 2010). When resilience is viewed from a strategic perspective, reconfigurations and enforcing changes occur before changes force a business to unwillingly change something at greater expense (Hamel and Välikangas, 2003; Välikangas, 2010). Maintaining continuous fulfilment of objectives stems mainly from the business continuity line of thought (Caralli, 2006). The infrastructure resilience literature discusses how to reduce the potential negative impact of disruptive events in terms of duration and magnitude (Vugrin et al., 2011), and how fast such systems recover to functionally sound status (Chen and Miller-Hooks, 2012). They often discuss how to model and measure resilience taking into account possible policy implications. However, when considering the infrastructure view we focused, in line with our objective, on resilience aspects related to operational performance rather than to policy implications.

Resilience views in systems engineering convey with them infrastructure and/or ecological study perspectives. A typical example is that of Cumming et al. (2005) in which they bring the two perspectives to discuss social-ecological resilience by studying the system level interaction as well as conceptual issues.. Further review on engineering perspective of resilience can be found in Francis and Bekera (2014).

Viewing these perspectives in combination provides a broader view of operational resilience. These perspectives are not mutually exclusive, instead they include important overlapping issues, connecting resilience perspectives at operational, organisational and industrial system levels (McDonald, 2006) as well as at corporate and strategic decision levels (Demmer et al., 2011). The frequency of the different resilience perspectives found in the reviewed literature is summarised in Appendix C. The number of papers adopting the perspectives is more than 41 because some papers contain more than one perspective.

\subsection{Operational resilience continuum}

\subsubsection{Downside threats and upside opportunities}

Resilience as a dynamic capability helps align decisions while taking into account prevailing uncertainties. Uncertainties always entail threats and opportunities, i.e. the "upside" and the "downside" (Frost et al., 2000; Hamel and Välikangas, 2003; Waters, 2007) of unanticipated changes. The same notion is well established in the risk theory domain. The definition of risk provided by Eugene Rosa (1998) states "risk is a situation or event where something of human value (including humans themselves) is at stake and where the outcome is uncertain", while risk definition in the ISO Guide 73 (ISO 2009) states "[Risk is the] effect of uncertainty on objectives". According to Aven and Renn (2009), these definitions belong to the category of definitions that express risk using events and uncertainties. More specifically, these risk definitions contain three properties: (1) the accommodation of both desirable and undesirable outcomes (i.e., opportunities and threats), (2) dealing with uncertainties rather than probabilities and expected values, and (3) consideration of outcome stakes rather than specific consequences. The second and third properties imply that uncertainties about a phenomenon appear in either one, or in a combination of two categories: epistemic and aleatory uncertainties (Paté-Cornell, 1996). Epistemic uncertainties describe the total lack of, or incomplete knowledge about the phenomenon under question, while aleatory uncertainties express the variability inherent in the phenomenon under consideration. The first property, that concerns opportunities and threats, interests us the most because it is a defining parameter for the scope of operational resilience as uncertainties relate to the risk continuum (Frost et al., 2000). Solely considering either threats or opportunities yields only a partial picture as these "co-exist" in uncertain circumstances.

Hamel and Välikangas (2003) discuss the utilisation of inherent resilience capabilities to explore opportunities for intentionally transforming strategies to sustain a growing business. Their argument is based on the logic that profit margins narrow from time to time, which could eventually lead to disappointment and a change of leadership, and would inevitably lead to unintentional strategy changes. Rather than having to experience these traumatic changes, they advocate evolutionary strategic shifts that adjust to the uncertain future. 
McManus et al. (2007) view exploitation of threats and opportunities in uncertainties in relation to the level of situational awareness in the organisation. If the organisation has low awareness about possible negative or positive consequences of a potential event, then their readiness to exploit opportunities would also be limited. Ismail et al. (2011) argue that businesses should build on unique resilience capabilities to exploit emerging business opportunities, an action that unavoidably exposes them to other challenges or threats.

\subsubsection{Proactive and reactive measures in operational resilience}

Capabilities related to operational resilience can be regarded as proactive or reactive. Proactive capabilities, as the name implies, are related to interventions made in anticipation of possible disruptions (Craighead et al., 2007). The intention is to use them in deterring the occurrence and the effects of threats while trying to exploit opportunistic circumstances to the maximum possible. Actions related to assessing near-misses and encountered misfortunes, searching for rare unexpected patterns as well as symptoms of unusual situations can be regarded as proactive (Sheffi, 2007; Weick and Sutcliffe, 2007). Reactive capabilities are aimed at helping to recover from disruptions and seize potential opportunities once the events have materialised (Chen and Miller-Hooks, 2012; Rice and Caniato, 2003; Scholz et al., 2012). While the contribution of learning and readiness built through proactive capabilities is undoubtedly important, resilience capability cannot be complete without having reactive capabilities as well (Craighead et al., 2007). It is through the occurrence of the events that the level of resilience built into the system is put to real measurable test. An operationally resilient enterprise always attempts to develop proactive "working hypotheses" before the emergence of new paths in face of uncertainties (Knemeyer et al., 2009), and reactively take quick action (Rice and Caniato, 2003) once the change events have been observed.

Instances of anecdotal and case based evidence on the application of proactive capabilities to deal with disruptions have been reported in few publications. For example, Sheffi and Rice (2005) provide examples which illustrate the application of proactive measures aiming at better resilience in managing disruptions. Close relationships established with suppliers enabled Toyota to shift its sourcing base during the 1997 Aisin fire incident. Delaying commitment and customisation proactively was a source of better profitability for Dell during the 1999 Taiwan earthquake. Nokia's victory over Ericsson following a fire at their common supplier's plant in the year 2000 was mainly attributed to the established processes for detecting the symptoms for, and managing disruptions. Restructuring multi-disciplinary teams, a sense of urgency, prompt decision making on next best alternatives are examples of proactive capabilities. Several other examples are also discussed in Sheffi (2007).

Reactive measures are undertaken after the occurrence of an unexpected disruption or opportunistic event (Craighead et al., 2007). The use of reactive capabilities following disruptive events is much more apparent and evident compared to proactive measures. Relatively large numbers of practical examples are reported in academic literature (e.g., Norrman and Jansson, 2004; Sheffi, 2007). However, there is little literature pinpointing and connecting specific practice routines or actions to proactive and reactive resilience capabilities.

\subsubsection{Operational versus supply chain resilience}

There seems to be more vagueness in what is in the scope of the supply chain perspective and what of the operational resilience perspective than is the case with the other perspectives of resilience in management research. Perhaps operational resilience issues have so often been discussed in the context of the supply chain perspective that scant attention has been given to them. Obviously, there is significant overlap between elements in the two resilience views, but there are interesting differences as well.

In supply chain resilience literature fewer roles (of the several that can be simultaneously assumed by an enterprise) are in focus. In the operational resilience perspective, the diversity of roles that the organisation simultaneously assumes is linked to its core business processes. The availability of redundancies and slacks (in the form of physical assets, inventories, etc.) is considered a source of resilience capabilities (Christopher and Peck, 2004) in the supply chain view, and therefore higher resource utilisation would be considered to increase the vulnerability of the system. In contrast, in operational resilience focus is directed to actions that help build dynamic capabilities which can be used to refresh, reconfigure and integrate tangible assets as well as relationships with other business actors. Inventory and physical asset buffers are not necessarily considered to be the most economical options for better resilience (i.e. inventory hit by tsunami is no better than the facilities damaged by same).

Another difference is that mainly disruptive events are considered in supply chain resilience and opportunistic circumstances are given less attention. Furthermore, primary focus is on supply side disruptions (Craighead et al., 2007) with low probabilities and high impact (Pettit et al., 2010). Additionally, the underlying assumption is that the firm under discussion must have some bargaining power over others in order to appear resilient. The operational resilience perspective focuses on the inherent capabilities of a given firm in terms of core processes (supplier, internal and customer focused). Capabilities embedded somewhere in the supply chain may also help, but the perspective suggests that firms rely on actions that help build inherent dynamic 
capabilities. Even firms with "lower bargaining power" can be operationally more resilient. They may also be sources of embedded capabilities for resilience in other firms belonging to similar supply chains regardless of role. Because dynamic capabilities are not hierarchy specific, as discussed for example in Arena et al., (2013), operational resilience provides an option to view different management levels or subsystems in an integrative manner.

\subsection{Identification of the core operational resilience functions}

Out of the 41 publications reviewed, 25 contain formal definitions (their own or adopted from others) of what resilience is in their study context. These publications are shown in table 1 . The remaining 16 publications did not provide explicit definitions of resilience (table 2). In this case implicit discussion on resilience is used to investigate which core functions have been reflected in the studies. Based on our review of the definitions and descriptive discussions of resilience, operational resilience in business enterprises can be seen to comprise five broadly set core functions: sense, build, reconfigure, re-enhance, and sustain. The following paragraphs briefly discuss each core function.

Sense. Resilience is essential in dealing with unanticipated changes and pressures (the so-called unknown unknowns) in the business environment. Therefore, the sense core function is related to how firms try to improve visibility and early detection. Indicative patterns and proxies help detect influential changes and their potential influence (Oh and Teo, 2006). Terms like "warning capability” and "situational awareness" are used in the literature to describe this core function (Craighead et al., 2007; McManus et al., 2007). The assumption behind this core function is that there are latent or early symptoms before the actual disorder is actually felt in the business operations. Analysing previous incidents faced (also by other firms), and those circumstances that deviated from the normal or expected is an important characteristic of sensing (Park et al., 2013). It also incorporates scenario-based analysis to improve expertise, experience and asset base for possible future shocks.

Firms that sense and anticipate circumstances more critically than their rivals benefit much more from a situation that both have little knowledge on. In the classical Nokia and Ericsson case, exploitation of opportunities attached to the uncertainties by the former amplified competitive threats for the latter (leading to severe losses) while both firms faced similar uncertainties. Obviously Nokia had better sensing capabilities than Ericsson during that incident. Readers may refer to the details of the case in Sheffi (2007), Sheffi and Rice (2005) or elsewhere to read how Nokia's urgency in demanding for explanations and solutions to delays in deliveries from a supplier compares to Ericsson's slower reaction.

Analysis of near-misses can also be seen as part of the sense core function. It helps increase awareness about potential disorders or opportunistic circumstances (Sheffi, 2007). By so doing, firms can proactively build capabilities to reduce not only the disorders but also similar near-misses in the future. However, sensing is not limited to experience of repetition. Rather, it is more focused on migrating analyses and decisions to a wider perspective and making use of experience gained from a circumstance to other transferable instances. In essence it is therefore strongly connected to mindfully searching for patterns, deviations and disparities even if they may appear to be minor (Weick and Sutcliffe, 2007). Shaping expectations is thus a critical issue for teams and individuals in anticipating and managing issues that are less expected. An organisation with good sense capabilities is able to anticipate unexpected events. It also learns in real time from developing events how to enhance favourable consequences and hinder unwanted ones (Francis and Bekera, 2014).

IT infrastructure plays an important role in realising the sense core function of operational resilience (Oh and Teo, 2006). Regardless of the sector the firm operates in, IT facilities can provide ample opportunities for relevant insights and real time data analysis opportunities to foster the building of relevant dynamic capabilities.

Build. Sensing alone does not help a firm to obtain and maintain operational resilience. Building proper capabilities inherently or acquiring them from somewhere is vitally important for proactive and reactive responses. The build core function signifies a set of activities carried out proactively. Usually these are executed prior to encountering changing circumstances or starting immediately after the encounter, depending on the firm's responsiveness (Sheffi and Rice, 2005).

The build core function has to do with broadening asset and capabilities bases through the use of uncommitted resources such as informal networks as much as possible (Weick and Sutcliffe, 2007). Resources dedicated to remaining "idle" waiting to be utilised when and if some unexpected event happens are costly for firms. A suggested remedy is to build more dynamic capability slacks whenever appropriate because resilience entails an efficient way of adjusting to changes (Francis and Bekera, 2014) with the help of variants of dynamic capabilities (Teece, 2007) that are built from routines (Peng et al., 2008).

Re-configure. Depending on decision preferences and available capabilities, the firm attempts to respond to unanticipated circumstances that have important impact. The response could be realized at two levels. At the lower level, the firm tries to make relatively small incremental changes in order to adapt to prevailing circumstances. At a higher level, the firm may need to reconfigure its structure, assets, etc. to deal with long term consequences with strategic implications and competitive advantage considerations. Thus, we can say 
reconfiguration is a higher (and integrative) form of adaptive capability of a firm with better operational resilience.

Different papers on resilience include discussions on resisting the influence of disruptive changes and on coping mechanisms or mitigations (Craighead et al., 2007). Firms may need different (multiple) forms of agility features to reconfigure what, how and when they do in responding to unanticipated changes. The main point of being able to reconfigure faster and better to cope with unexpected incidents is that firms do not need to maintain redundancies in terms of physical resources (Zhao et al., 2011). They can build higher level capabilities from existing ones and proceed with reconfiguration as necessary.

While adaptive capabilities do not exclude responses aimed at enhancing opportunities, the majority of studies we reviewed define and discuss them in terms of facing threats and disruptions only. A common misconception about adapting to a changing business environment is that the adaptation is considered to take place on the supply side only. That is, companies focus on to amending their sourcing approaches, including changes to their supply base, in order to ensure the delivery of their products. But adaptation could also mean influencing the demand side in a constructive way (revenue management). After the 1999 Taiwan earthquake, Dell was able to adapt its assemble-to-order manufacturing strategy to provide customers with computers assembled only from parts available (from sources other than Taiwan) at attractive price discounts and in doing so increased its overall revenue significantly (Sheffi and Rice, 2005).

Re-enhance. This core function concerns retaining competitive performance levels once the effects of shocks or pressures are felt. Recovery is mainly concerned with disruptive events (Christopher and Peck, 2004; Sheffi, 2007). Firms try to enhance gains from opportunities before they become threats (e.g., Hamel and Välikangas, 2003). If performance has been affected negatively or there are potential opportunities for further improving performance, a re-enhancing capability is of vital importance. The use of the term re-enhance helps us to encompass both recovering from disruptive and enhancing opportunistic events. It also places a stronger emphasis on re-attaining performance levels equal to, or better than, the levels prevailing before the emergence of the incident. According to the disruption profile of Sheffi and Rice (2005), performance affected by a disruption is measured relative to a constant reference before and after the disruption to measure how well an enterprise recovered. However this reference may change after the disorder depending on prevailing circumstances. Therefore, it may not be enough to re-attain a performance level equal to pre-incident level as the value expectation of customers might have increased. Opportunities could also result from the incident that, if not exploited to increase performance, would leave the firm in a less competitive position.

Sustain. The essence of adapting or reconfiguring is to sustain the attainment of business objectives (i.e., delivery function). Continuing to perform in one manner or another is an important feature that reduces the unwanted long-term consequences of stopping and later recovering (e.g., McManus et al., 2007). For example, during an event customers may become disappointed with the firm's capabilities and switch to alternative suppliers and, in the worst case, may never come back again (Sheffi, 2007).

As discussed in resilience literature in the infrastructure protection domain, facilities may rapidly resume functioning at higher levels of expenditure, sometimes even if it means functioning with extended losses. In business firms, however, sustaining a level of performance is reflected in efforts that help to keep profitability at a fair level. If some additional costs have to be incurred, they need to provide sufficiently justified value and keep customers from leaving.

Table 1 illustrates how these five core functions are reflected in resilience definitions found in the reviewed literature. It is clear to see that the sense and sustain core functions have been given less consideration when defining resilience from supply chain, organisational, strategic and infrastructure perspectives. However, all the definitions include most of the core functions and this makes them relevant for identifying the core functions of operational resilience.

\section{Please insert Table 1 about here}

Table 2 shows the core functions found in the discussions in publications without a formal definition of resilience. The pattern of lower emphasis for sense and build core functions appears similar to the one in table 1.The re-configure and re-enhance core functions have been recognised in all publications included in tables 1 and 2. As already mentioned, reconfiguration includes adaptation to changing circumstances that range from minor changes to significant reconfiguration. But most papers put more emphasis on adaptation. Re-enhance includes recovering fast and effectively as well enhancing opportunities revealed by changing circumstances. However, many of the publications recognise only recovery from disruptive events. 


\section{Please insert Table 2 about here}

If we look at the core functions from a time horizon point of view, sense and build focus on firms' processes of utilising and rearranging strategic assets before and upon encountering an unanticipated change event. They are also referred to as preparedness or readiness. Re-configure and sustain core functions reflect on actions during and after the incident has materialised. The reconfigure core function is mainly reactive, but may also be anticipative in reference to unexpected incidents and in relationship with sense functions. Indeed, the core functions take place repetitively, though not necessarily in a fixed sequence, in order to maintain better resilience in the ever changing, circumstances.

Having identified the core functions, we define operational resilience of a business enterprise as encompassing dynamic capabilities to sense, build, reconfigure, and re-enhance in the face of uncertainties in being able to sustain operational performance.

\subsection{Operational resilience core functions versus dynamic capabilities}

As previously mentioned, the dynamic capabilities perspective relates to capabilities that are dynamic in nature and help entities refresh existing capabilities (Teece, 2007; Teece et al., 1997). They are often categorised as learning, reconfiguration, integration/coordination, and delivery typologies. The five core functions of operational resilience identified in this study can be mapped to these categories. A preliminary view of such a mapping appears in table 3, which summarises proactive and reactive practice routines related to the operational resilience core functions that can be seen as dynamic capabilities. The implication is, that by identifying and systematically utilizing routines businesses can build various forms of dynamic resilience capabilities that can be used to proactively prepare against uncertainties and to reactively manage the unexpected.

\section{Please insert Table 3 about here}

\section{Operational resilience core functions with case examples}

\subsection{Case 1: Dell and the West Coast ports lockout}

In the year 2002, the 29 West Coast ports in the USA extending from Los Angeles to Chicago were closed for roughly ten days due to a longshoremen's strike and the subsequent lockout. Firms in different sectors were left with delayed incoming and outgoing deliveries for the upcoming Christmas season with inventories piled up at harbours and on-board ships waiting for loading or unloading (Breen, 2004; Sheffi, 2007). The situation was particularly disruptive for perishable items and small inventory-carrying companies.

Dell, one of the firms faced with the situation, was expected to be hit hard during this crisis as it follows a lean production approach, and had parts inventories enough only for hours of production. Contrary to expectations, rather than being severely affected by the situation, Dell was able to outperform the competition (Breen, 2004; Pettit et al., 2010). Dell used its internal capabilities to rearrange product configurations. Dell's management also made early deals with airfreight service providers to secure deliveries ahead of others. They were also able to bargain for much cheaper freight costs compared to other firms that contacted air cargo carriers late (Breen, 2004). The example demonstrates how Dell showed a high level of resilience when faced with an uncertain situation that had been expected to significantly disrupt its operations and consequently affect its business. Dell not only managed the disruption, it also succeeded in directing its capabilities during the crisis to gain competitive advantages relative to other firms (Breen, 2004; Rice and Caniato, 2003).

Let us look at Dell's actions in light of the core operational resilience functions.

Sense. Most of the firms using the West Coast ports for their inbound and outbound logistics had more or less the same information about the upcoming longshoremen's strike at essentially the same time. So, in these respects nothing differentiated Dell from its competitors. Interestingly, Dell was able to anticipate possible scenarios immediately after the strike began, as well as after the harbours went operational again. Some key points include:

(1) Dell's management understood that competitors would start looking for alternative means of securing supplies (i.e. airfreight), and started making moves to secure this alternative first;

(2) After the harbours reopened, Dell made sure that remedies were in place to solve the problem of sorting and clearing cargo despite the large amounts of cargo stranded in the port;

(3) Dell used the lockout as an opportunity to demand its suppliers change from bulky CRT monitors to lighter and technologically superior LCD monitors. The aim here was not only to solve the problem at 
hand (i.e. lighter weight for air cargo), but also to adopt a strategic direction for the long term (competitive advantage in rapidly introducing LCD monitors to customers) (Pettit et al., 2010).

Build. Dell held bargaining power over some (if not all) suppliers. While this may be seen as a negative aspect from the point of view of the suppliers, it also had positive implications for them. Dell was demanding responsiveness in delivery, cargo assortment, and re-routing of supplies from Taiwan, China, and Malaysia. Suppliers that complied with the requests (i.e. were more resilient and responsive than others) also benefitted through higher sales and better ratings from Dell.

Key Dell personnel were sent to the suppliers' factories and hub ports to coordinate and streamline cargo flows. The arrangements made with airfreight cargo companies also helped Dell to get faster and "cheaper" rentals (by the time other firms wanted to rent cargo planes, prices were almost double the ones Dell had obtained). In addition, Dell was able to load and fly the cargo planes quickly thus keeping down rental costs.

Reconfigure. Logistics re-routing to airfreight coupled with the decision on shifting to LCD monitors are part of reconfiguration issues. Ironically, many firms, when informed of the upcoming strike, tried to pull more cargo before the strike broke out hoping to pile up inventories for the Christmas sales season. Many of them also continued transporting cargo to the locked-out ports during the incident which dramatically increased the amount of cargo stranded, making clearance from ports even more cumbersome after ports were re-opened. Dell tried to adapt a modified logistics coordination process rather than piling up inventories. This is how the situation was reported in a newspaper: “...Even though Dell had PC components in hundreds of containers on 50 ships, it knew the exact moment when each would be cycled through the harbour, and it was among the first to unload its parts and speed them to its factories in Austin and Nashville...” (Breen, 2004). Other than that, Dell did not need to make any major structural reconfigurations. Perhaps they were convinced that it would be better to continue with the existing structure and business model, and make only adaptations necessary for securing suppliers and deliveries.

Re-enhance. It is clear how important rapid recovery and continued operation are for a firm like Dell that follows lean production and a direct-to-customer model. It ensured short delivery times to customers. This meant less space for fluctuations in such major lockout. Yet, Dell was able to re-enhance operations. The benefits of rapid recovery and opportunity enhancements at Dell are reflected in the financial statements. Dell was able to increase its net income by about 30\% compared to the previous year.

Sustain. Despite having inventory for only a few hours of production, Dell managed to limit the potential impact of the disruption on its lean, direct-to-customer model to a minimum. Even with the added cost of airfreight compared to marine transport, profit and sales volumes showed significant increases since the previous year. Dell utilised negotiated price deals with LCD monitor manufacturers by increasing purchase volumes and also reaped benefits for airfreight delivery from the lighter weight and smaller bulk of LCDs when compared to CRT monitors(Sheffi, 2007).

\subsection{Case 2: Manganese Bronze and the 2012 recall}

Manganese Bronze (MB), the manufacturer of the London black cabs, had been a success and an iconic part of the British auto industry until it was hit by declining sales and product recalls like many other automakers. The strategy set out by the holding company in 2011 was to increase quality and global sales of model TX4 cabs in a joint effort with its venture partner Geely (Manganese Bronze Holdings, 2011). This has come to effect with ownership of $23 \%$ shares of MB by Geely Group paying $£ 53$ million in 2006, and subsequent major restructuring of top management. As part of the business restructuring MB would distribute Geely's other car models in the UK to improve declining profit.

MB had become aware of some quality and logistics issues in 2011 after design and component sourcing had been moved to China in search of cost savings (Manganese Bronze Holdings, 2011). The five years before 2012 were marked by financial loses for MB (loss before tax of £7.3M, £2.6M and £6.3M in the years 2009, 2010 and 2011 respectively). As in many car manufacturers, MB's sales had been declining since 2008, and an upturn in sales, due to increased export sales mainly to the Middle East, in 2011 was not large enough eliminate losses (Manganese Bronze Holdings, 2011).

On October 12, 2012, MB had to announce a recall of about 400 TX4 model cabs due to problems in steering boxes that were sourced from China. Two incidents due to these problems - with no significant injuries to drivers or passengers - were reported a few weeks before the recall. And yet, a sale occurred hours before the recall. Prior to this one, MB had another recall in 2008 due to fire incidents in the engine compartment, costing the firm about £5M. The company has reported to incur £3.1M loss in the first six months of 2012 that later was discovered as an accounting error, and was corrected to £4.25M. The company has been blamed for not listening to the main customers (The London Taxi Company drivers) regarding the extent of the problem as reported in different media.

The recall coupled with the declining sales and huge loans led the firm to default. The shares of MB were down to 10 pence each on Oct. 11, 2012 just before they were suspended on London Stock Exchange, making 
the firm worth only £3M. Buy-out has been possible only after PricewaterhouseCoopers has been appointed administrator and Geely finally decided to buy MB several months later (Gribben, 2012; Jones, 2013). It is to be noted that MB has restarted producing the TX4 taxicabs at the Coventry plant by September 2013 under full ownership of Geely and is hoping to show profits in one year as opposed to previous three year projects to breakeven. Progresses from restart of production (if any) are not included in this study as no enough detail is available.

Now let us briefly see how a lack of operational resilience has been manifested in MB in terms of the core functions of operational resilience.

Sense. MB were fully aware of quality problems well in advance of the decisive 2012 recall. In fact, the symptoms were obvious and mentioned in annual reports stating "undergoing efforts to improve". However, any anticipation of the worst consequences and what could be done to resolve them seemed lacking. Apparently, they did not have enough competence to control the outsourced design operations, nor of ensuring quality and timely delivery from the Chinese supplier.

Build. MB was suffering financially in the 5 years before the 2012 recall. And perhaps, it was also experiencing many more problems in its organisation than was publicly known. The accounting errors, not reporting problems timely, and even understating their extent are some indicators. The employees were not sufficiently involved nor were their capabilities sufficiently recognised. The change of the supplier stemmed from ownership interests and direct cost cutting, rather than from mutually nurtured technical competence. There was no strong evidence of any integrated approach. MB clearly lacked the skill and expertise for the relationship with the supplier to work effectively.

Reconfigure. In $\mathrm{MB}$, the major organisational and financial arrangements and changes in product configuration did not result in better operational resilience. After Geely bought the first $23 \%$ of shares, they assigned a new member to the management team, and pumped in additional financing, but could not resolve the quality problems that led to the final recall and the subsequent default. A possible explanation is that such big reactive efforts would not be productive because sensing the uncertain circumstances and building capabilities proactively was limited.

Re-enhance. The discussion above shows that by the time the recall of 400 taxicabs, which represented a very significant portion of MB sales, the capability to pursue recovery efforts and enhance performance was extremely limited. This again demonstrates how reactive efforts rely heavily on undertaken proactive measures.

Sustain. The statement made by MB's management in conjunction with the recall stated that MB might not easily be able resume normal operations. The company failed to fulfil the expectations of customers (mainly drivers and passengers of the taxicabs) concerning the safety and the reliability of the vehicles, which are also regulatory requirements.

Announcements about adverse incidents in the firm (accounting errors, losses, quality problems, etc.) all collectively dragged the firm to a point where it could not return to normal operations without paying a high price. In our view, MB is a typical case that illustrates the lack of operational resilience dimensions that cannot be easily offset by just pumping in financial or physical resources. Resilience is an issue that transcends strategic, tactical and operational hierarchies as well as integrative approaches inherently built into the organisation.

\section{Conclusion and directions for future research}

This study has aimed to characterise operational resilience normatively. We have reviewed 35 journal articles, and six books and chapters on resilience in management research. Twenty-five of the total provide explicit definitions of resilience while the remaining 16 implicitly discuss it. Based on the reviews, five core functions of operational resilience (sense, build, reconfigure, re-enhance, sustain) were identified. A definition of operational resilience aligned with these five identified attributes was proposed and two case examples were eventually used to better scrutinise and discuss the identified core functions. The identification of the core functions was motivated by empirical challenges of applying theoretical development of the concept. This strengthens the practical relevance of the study in addition to its theoretical value. We further framed operational resilience as an integrative high-level concept that can be modelled with sub-attributes and directly observable indicators. The main practical implication of the study is that business decision makers can exploit routines that help establish better resilience capabilities in face unpredictable circumstances. With such insights, academics can provide better advices to managers on what they need to do in order to improve their chances of the successful implementation of strategies for better operational resilience.

In addition, the review revealed interesting gaps that could point to areas of potential future research. Referring to these gaps, we would like to offer some possible research directions.

Relevance of core operational resilience functions. Retrospective studies would be of help to confirm the relevance, to assess the relative importance, and also to highlight possible dependencies between those core functions, for example, by comparing the resilience performance of different companies that faced similar circumstances but relied on different sets of core functions. 
Taxonomy of operational resilience capabilities and related indicators. Starting from the proposed possible correspondence between core functions and dynamic capabilities, a taxonomy of resilience-oriented capabilities could be developed to guide operational resilience planning, diagnosis, and monitoring. To this end, a connected taxonomy of Key Operational Resilience Indicators should be developed as well. In this regard, theoretical and validation studies are needed. There is also a need for the validation of the multilevel construct of operational resilience using empirical data.

Synergies and trade-offs among capabilities to deal with threats versus opportunities. Given the full scope of operational resilience, covering the upside and downside consequences of uncertain events, a key question is whether or not threats and opportunities should be handled with the same set of dynamic capabilities. Is any synergy or trade-off mechanism in place between threat-oriented and opportunities-related dynamic capabilities? Answering these questions is crucial for both the operationalisation of the resilience concept and its integration in planning and control processes. This also leads to a potential research direction of the study of operational resilience in relation to lean thinking.

Operational resilience versus lean thinking. In resilience literature, the need to maintain redundancy of strategic assets (Christopher and Holweg, 2011) is frequently discussed. In the lean thinking paradigm redundancy needs to be minimised to reduce non-value-adding costs (waste), and boost efficiencies. Similarly, severe consequences due to disruptions in JIT deliveries are frequently cited as clear cases of poor supply chain resilience. Does this imply that operational resilience is essentially against the principles and implementation practices of lean thinking? Several scholars claim that lean thinking is suitable for a stable business environment, and that a "more resilient" strategy is required for turbulent environments (e.g., Christopher and Holweg, 2011; Christopher and Peck, 2004). On the other hand, some global companies following a lean strategy have performed better than their competitors when faced with a common dynamic unfavourable circumstances (Pettit et al., 2010). Could there be a scientific explanation? Could there be some "better capability" in the companies utilising some principles and tools that enables them to practice lean and resilience features together? How do operational resilience features improve competitive advantages? Answering such questions is nowadays vital for several companies competing in global markets, where continuous pressure on operational efficiency and speed, deep uncertainties on market dynamics, and vulnerabilities to emerging new risks frequently go hand in hand.

\section{References}

Adams, T.M., Bekkem, K.R. and Toledo-durán, E.J. (2013) 'Freight resilience measures', Journal of Transportation Engineering, Vol. 138 No. 11, pp.1403-1409.

Allen, P.M., Datta, P.P. and Christopher, M. (2006) 'Improving the resilience and performance of organizations using multi-agent modelling of a complex production-distribution systems', Risk Management, Vol. 8 No. 4, pp.294-309.

Amann, B. and Jaussaud, J. (2012) 'Family and non-family business resilience in an economic downturn', Asia Pacific Business Review, Vol. 18 No. 2, pp.203-223.

Ambrosini, V. and Bowman, C. (2009) 'What are dynamic capabilities and are they a useful construct in strategic management?', International Journal of Management Reviews, Vol. 11 No. 1, pp.29-49.

Arena, M., Azzone, G., Cagno, E., Ferretti, G., Prunotto, E., Silvestri, A. and Trucco, P. (2013) 'Integrated Risk Management through dynamic capabilities within project-based organizations: The Company Dynamic Response Map', Risk Management, Vol. 15 No. 1, pp.50-77.

Aven, T. (2012) 'Foundational issues in risk assessment and risk management', Risk Analysis, Vol. 32 No. 10, pp.1647-1656.

Aven, T. and Renn, O. (2009) 'On risk defined as an event where the outcome is uncertain', Journal of Risk Research, Vol. 12 No. 1, pp.1-11.

Bhamra, R., Dani, S. and Burnard, K. (2011) 'Resilience: the concept, a literature review and future directions', International Journal of Production Research, Vol. 49 No. 18, pp.5375-5393.

Boin, A. and van Eeten, M.J.G. (2013) 'The resilient organization', Public Management Review, Vol. 15 No. 3 , pp.429-445.

Brand, F.S. and Jax, K. (2007) 'Focusing the meaning(s) of resilience: Resilience as a descriptive concept and a boundary object', Ecology and Society, Vol. 12 No. 1. [Online] http://www.ecologyandsociety.org/vol12/iss1/art23/ (Accessed 02 May 2014)

Breen, B. (2004,November) 'Living in Dell time', Fast Company.

Burnard, K. and Bhamra, R. (2011) 'Organisational resilience: Development of a conceptual framework for organisational responses', International Journal of Production Research, Vol. 49 No. 18, pp.5581-5599.

Caniato, F., Caridi, M., Castelli, C. and Golini, R. (2011) 'Supply chain management in the luxury industry: A first classification of companies and their strategies', International Journal of Production Economics, Vol. 133 No. 2, pp.622-633. 
Caralli, R.A. (2006) Sustaining operational resiliency: A process improvement approach to security management, Carnegie Mellon University.

Carpenter, S., Walker, B.H., Anderies, J.M. and Abel, N. (2001) 'From metaphor to measurement: Resilience of what to what?', Ecosystems, Vol. 4 No. 8, pp.765-781.

Carvalho, H., Duarte, S. and Cruz-Machado, V. (2011) 'Lean, agile, resilient and green: divergencies and synergies', International Journal of Lean Six Sigma, Vol. 2 No. 2, pp.151-179.

Chen, L. and Miller-Hooks, E. (2012) 'Resilience: An indicator of recovery capability in intermodal freight transport', Transportation Science, Vol. 46 No. 1, pp.109-123.

Christopher, M. and Holweg, M. (2011) '“Supply chain 2.0”: managing supply chains in the era of turbulence', International Journal of Physical Distribution \& Logistics Management, Vol. 41 No. 1, pp.63-82.

Christopher, M. and Peck, H. (2004) 'Building the resilient supply chain', International Journal of Logistics Management, Vol. 15 No. 2, pp.1-13.

Colicchia, C., Dallari, F. and Melacini, M. (2010) 'Increasing supply chain resilience in a global sourcing context', Production Planning \& Control, Vol. 21 No. 7, pp.680-694.

Coutu, D.L. (2002) 'How resilience works', Harvard Business Review, Vol. 80 No. 5, pp.46-55.

Craighead, C.W., Blackhurst, J., Rungtusanatham, M.J. and Handfield, R.B. (2007) 'The severity of supply chain disruptions: Design characteristics and mitigation capabilities', Decision Sciences, Vol. 38 No. 1, pp.131-156.

Cumming, G.S., Barnes, G., Perz, S., Schmink, M., Sieving, K.E., Southworth, J., Binford, M., et al. (2005) 'An exploratory framework for the empirical measurement of resilience', Ecosystems, Vol. 8 No. 8, pp.975987.

Demmer, W.A., Vickery, S.K. and Calantone, R. (2011) 'Engendering resilience in small- and medium-sized enterprises (SMEs): A case study of Demmer Corporation', International Journal of Production Research, Vol. 49 No. 18, pp.5395-5413.

Francis, R. and Bekera, B. (2014) 'A metric and frameworks for resilience analysis of engineered and infrastructure systems', Reliability Engineering \& System Safety, Vol. 121, pp.90-103.

Frost, C., Allen, D., Porter, J. and Bloodworth, P. (2000) Operational risk and resilience: Understanding and minimizing operational risk to secure shareholder value, Elsevier, London.

Gribben, R. (2012,October22) 'Black cab maker Manganese Bronze to appoint administrators', The Telegraph. [Online] www.telegraph.co.uk

Haimes, Y.Y. (2009) 'On the definition of resilience in systems', Risk Analysis, Vol. 29 No. 4, pp.498-501.

Hamel, G. and Välikangas, L. (2003) 'The quest for resilience', Harvard Business Review, Vol. 81 No. 9, pp.5263.

Hearnshaw, E.J.S. and Wilson, M.M.J. (2013) 'A complex network approach to supply chain network theory', International Journal of Operations \& Production Management, Vol. 33 No. 4, pp.442-469.

Hémond, Y. and Robert, B. (2012) 'Preparedness: the state of the art and future prospects', Disaster Prevention and Management, Vol. 21 No. 4, pp.404-417.

Holling, C.S. (1973) 'Resilience and sustainability of ecological systems', Annual Review of Ecology and Systematics, Vol. 4, pp.1-23.

Holling, C.S. (1996) 'Engineering resilience versus ecological resilience', Engineering Within Ecological Constraints, pp.31-43.

Hollnagel, E. (2006) 'Resilience - the challenge of the unstable', in Hollnagel, E., Woods, D.D. and Leveson, N. (Eds.), Resilience engineering: Concepts and precepts, Ashgate, Burlington, USA, pp. 9-17.

International Standards Organization. (2009) ISO 31000: Risk management — Principles and guidelines, Geneva, ISO.

Ismail, H.S., Poolton, J. and Sharifi, H. (2011) 'The role of agile strategic capabilities in achieving resilience in manufacturing-based small companies', International Journal of Production Research, Vol. 49 No. 18, pp.5469-5487.

Johnson, N., Elliott, D. and Drake, P. (2013) 'Exploring the role of social capital in facilitating supply chain resilience', Supply Chain Management: An International Journal, Vol. 18 No. 3, pp.324-336.

Jones, R. (2013,February1) 'China's Geely buys black cab maker Manganese Bronze', Reuters.

Jüttner, U. and Maklan, S. (2011) 'Supply chain resilience in the global financial crisis: An empirical study', Supply Chain Management: An International Journal, Vol. 16 No. 4, pp.246-259.

Knemeyer, A.M., Zinn, W. and Eroglu, C. (2009) 'Proactive planning for catastrophic events in supply chains', Journal of Operations Management, Vol. 27 No. 2, pp.141-153.

Lee, A. V., Vargo, J. and Seville, E. (2013) 'Developing a tool to measure and compare organizations' resilience', Natural Hazards Review, Vol. 14, pp.29-41.

Lewis, M.A. (2003) 'Cause, consequence and control: towards a theoretical and practical model of operational risk', Journal of Operations Management, Vol. 21, pp.205-224.

Manganese Bronze Holdings. (2011) Annual results to December 2011, London, MBH. 
Manyena, S.B. (2006) 'The concept of resilience revisited', Disasters, Vol. 30 No. 4, pp.433-50.

McDonald, N. (2006) 'Organisational resilience and industrial risk', in Hollnagel, E., Woods, D.D. and Leveson, N. (Eds.), Resilience Engineering: Concepts and percepts, Ashgate, Burlington, USA, pp. 155-180.

McManus, S.T., Seville, E., Brunsdon, D. and Vargo, J. (2007) Resilience management: A framework for assessing and improving the resilience of organisations ( No. 2007/01), New Zealand, Resilient Organizations Program.

Melnyk, S.A., Davis, E.W., Spekman, R.E. and Sandor, J. (2010) 'Outcome-driven supply chains', MIT Sloan Management Review, Vol. 51 No. 2, pp.33-38.

Norrman, A. and Jansson, U. (2004) 'Ericsson's proactive supply chain risk management approach after a serious sub-supplier accident', International Journal of Physical Distribution \& Logistics Management, Vol. 34 No. 5, pp.434-456.

Oh, L.-B. and Teo, H.-H. (2006) 'The impacts of information technology and managerial proactiveness in building net-enabled organizational resilience', in Donnellan, B., Larsen, T., Levine, L. and DeGross, J. (Eds.), The Transfer and Diffusion of Information Technology for Organizational Resilience, IFIP, Vol. 206, Springer, Boston, pp. 33-50.

Park, J., Seager, T.P., Rao, P.S.C., Convertino, M. and Linkov, I. (2013) 'Integrating risk and resilience approaches to catastrophe management in engineering systems', Risk Analysis, Vol. 33 No. 3, pp.356-367.

Paté-Cornell, E. (1996) 'Uncertainties in risk analysis : Six levels of treatment', Reliability Engineering \& System Safety, Vol. 54 No. 2-3, pp.95-111.

Peng, D., Schroeder, R. and Shah, R. (2008) 'Linking routines to operations capabilities: A new perspective', Journal of Operations Management, Vol. 26 No. 6, pp.730-748.

Pettit, T.J., Fiksel, J. and Croxton, K.L. (2010) 'Ensuring supply chain resilience: Development of a conceptual framework', Journal of Business Logistics, Vol. 31 No. 1, pp.1-22.

Ponomarov, S.Y. and Holcomb, M.C. (2009) 'Understanding the concept of supply chain resilience', The International Journal of Logistics Management, Vol. 20 No. 1, pp.124-143.

Prior, T. and Hagmann, J. (2013) 'Measuring resilience: Methodological and political challenges of a trend security concept', Journal of Risk Research, pp.1-18.

Rice, J.B. and Caniato, F. (2003) 'Building a secure and resilient supply network', Supply Chain Management Review, Vol. 7 No. 5, pp.22-30.

Rosa, E.A. (1998) 'Metatheoretical foundations for post-normal risk', Journal of Risk Research, Vol. 1 No. 1 , pp.15-44.

Scholz, R.W., Blumer, Y.B. and Brand, F.S. (2012) 'Risk, vulnerability, robustness, and resilience from a decision-theoretic perspective', Journal of Risk Research, Vol. 15 No. 3, pp.3133-330.

Sheffi, Y. (2007) The resilient enterprise: Overcoming vulnerability for competitive advantage, MIT Press, Cambridge, MA.

Sheffi, Y. and Rice, J.B. (2005) 'A supply chain view of the resilient enterprise', MIT Sloan Management Review, Vol. 47 No. 1, pp.40-48.

Silvestri, A., Arena, M., Cagno, E., Trucco, P. and Azzone, G. (2011) 'Enterprise risk management from theory to practice: The role of dynamic capabilities approach - the "Spring” model', in Wu, D.D. (Ed.), Quantitative Financial Risk Management, Springer, London, pp. 281-307.

Spiegler, V.L.M., Naim, M. and Wikner, J. (2012) 'A control engineering approach to the assessment of supply chain resilience', International Journal of Production Research, Vol. 50 No. 21, pp.6162-6187.

Stephenson, J., Vargo, J. and Seville, E. (2010) 'Measuring and comparing organisational resilience in Auckland', The Australian Journal of Emergency Management, Vol. 25 No. 2, pp.27-32.

Sullivan-Taylor, B. and Branicki, L. (2011) 'Creating resilient SMEs: Why one size might not fit all', International Journal of Production Research, Vol. 49 No. 18, pp.5565-5579.

Supply Chain Council. (2010) Supply chain operations reference (SCOR) model, SCC, Cypress.

Tang, C.S. (2006) 'Perspectives in supply chain risk management', International Journal of Production Economics, Vol. 103 No. 2, pp.451-488.

Teece, D.J. (2007) 'Explicating dynamic capabilities: The nature and microfoundations of (sustainable) enterprise performance', Strategic Management Journal, Vol. 28 No. 13, pp.1319-1350.

Teece, D.J., Pisano, G. and Shuen, A. (1997) 'Dynamic capabilities and strategic management', Strategic Management Journal, Vol. 18 No. 7, pp.509-533.

Tveiten, C.K., Albrechtsen, E., Wærø, I. and Wahl, A.M. (2012) 'Building resilience into emergency management', Safety Science, Vol. 50 No. 10, pp.1960-1966.

Välikangas, L. (2010) The resilient organization: How adaptive cultures thrive even when strategy fails, McGraw-Hill, New York.

Véronneau, S., Cimon, Y. and Roy, J. (2013) 'A model for improving organizational continuity', Journal of Transportation Security, Vol. 6 No. 3, pp.209-220. 
Vugrin, E.D., Warren, D.E. and Ehlen, M.A. (2011) 'A resilience assessment framework for infrastructure and economic systems: Quantitative and qualitative resilience analysis of petrochemical supply chains to a hurricane', Process Safety Progress, Vol. 30 No. 3, pp.281-290.

Walker, B.H., Holling, C.S., Carpenter, S.R. and Kinzig, A. (2004) 'Resilience, adaptability and transformability in social - ecological systems', Ecology and Society, Vol. 9 No. 2, p.5.

Waters, D. (2007) Supply chain risk management: vulnerability and resilience for logistics, Kogan-Page, London.

Weick, K.E. and Sutcliffe, K.M. (2007) Managing the unexpected: Resilient performance in an age of uncertainty, 2nd ed., John WIley \& Sons, San Fransisco, CA.

Zhao, K., Kumar, A., Harrison, T.P. and Yen, J. (2011) 'Analyzing the resilience of complex supply network topologies against random and targeted disruptions', IEEE Systems Journal, Vol. 5 No. 1, pp.28-39. 


\section{Tables}

Table 1. Publications with explicit definition provided or clear reference made

\begin{tabular}{|c|c|c|c|c|c|c|c|c|c|c|c|c|c|c|c|}
\hline \multirow{2}{*}{$\begin{array}{l}\text { Operational } \\
\text { resilience core } \\
\text { functions }\end{array}$} & \multicolumn{15}{|c|}{ Publications } \\
\hline & $\mathrm{P} 1$ & $\mathrm{P} 2$ & P3 & P4 & P5 & P6 & P7 & P8 & P9 & P10 & P11 & P12 & P13 & P14 & P15 \\
\hline Sense & & & & $\checkmark$ & $\checkmark$ & $\checkmark$ & $\checkmark$ & $\checkmark$ & $\checkmark$ & & & $\checkmark$ & $\checkmark$ & & $\checkmark$ \\
\hline Build & & $\checkmark$ & $\checkmark$ & $\checkmark$ & $\checkmark$ & $\checkmark$ & $\checkmark$ & $\checkmark$ & & $\checkmark$ & & $\checkmark$ & $\checkmark$ & & $\checkmark$ \\
\hline Re-configure & $\checkmark$ & $\checkmark$ & $\checkmark$ & $\checkmark$ & $\checkmark$ & $\checkmark$ & $\checkmark$ & $\checkmark$ & $\checkmark$ & $\checkmark$ & $\checkmark$ & $\checkmark$ & $\checkmark$ & $\checkmark$ & $\checkmark$ \\
\hline Sustain & $\checkmark$ & & & $\checkmark$ & & $\checkmark$ & $\checkmark$ & $\checkmark$ & $\checkmark$ & $\checkmark$ & $\checkmark$ & $\checkmark$ & $\checkmark$ & $\checkmark$ & \\
\hline Re-enhance & $\checkmark$ & $\checkmark$ & $\checkmark$ & $\checkmark$ & $\checkmark$ & $\checkmark$ & $\checkmark$ & $\checkmark$ & $\checkmark$ & $\checkmark$ & $\checkmark$ & $\checkmark$ & $\checkmark$ & $\checkmark$ & $\checkmark$ \\
\hline Core functions & P16 & $\mathrm{P} 17$ & P18 & P19 & $\mathrm{P} 20$ & $\mathrm{P} 21$ & $\mathrm{P} 22$ & P23 & P24 & P25 & & & & & \\
\hline Sense & & & & $\checkmark$ & $\checkmark$ & & & $\checkmark$ & & & & & & & \\
\hline Build & & $\checkmark$ & & $\checkmark$ & $\checkmark$ & $\checkmark$ & & $\checkmark$ & $\checkmark$ & $\checkmark$ & & & & & \\
\hline Re-configure & $\checkmark$ & $\checkmark$ & $\checkmark$ & $\checkmark$ & $\checkmark$ & $\checkmark$ & $\checkmark$ & $\checkmark$ & $\checkmark$ & $\checkmark$ & & & & & \\
\hline Sustain & $\checkmark$ & & $\checkmark$ & $\checkmark$ & $\checkmark$ & $\checkmark$ & $\checkmark$ & $\checkmark$ & $\checkmark$ & & & & & & \\
\hline Re-enhance & $\checkmark$ & $\checkmark$ & $\checkmark$ & $\checkmark$ & & $\checkmark$ & $\checkmark$ & $\checkmark$ & $\checkmark$ & $\checkmark$ & & & & & \\
\hline
\end{tabular}

P1: (Frost et al., 2000); P2: (Hamel and Välikangas, 2003); P3: (Christopher and Peck, 2004); P4: (McDonald, 2006); P5: (Sheffi, 2007); P6: (Ponomarov and Holcomb, 2009); P7: (Välikangas, 2010); P8: (Stephenson et al., 2010); P9: (Zhao et al., 2011); P10: (Hearnshaw and Wilson, 2013); P11: (Hémond and Robert, 2012); P12: (Johnson et al., 2013); P13: (Lee et al., 2013); P14: (Amann and Jaussaud, 2012); P15: (Boin and van Eeten, 2013); P16: (Adams et al., 2013); P17: (Chen and Miller-Hooks, 2012); P18:

(Cumming et al., 2005); P19: (Prior and Hagmann, 2013); P20: (Oh and Teo, 2006); P21:(Véronneau et al., 2013); P22:(Vugrin et al., 2011); P23: (Spiegler et al., 2012); P24: (Haimes, 2009); P25: (Scholz et al., 2012) 
Table 2. Publications from which resilience core functions have been inferred from implicit discussion

\begin{tabular}{|c|c|c|c|c|c|c|c|c|c|c|c|c|c|c|c|c|}
\hline \multirow{2}{*}{$\begin{array}{l}\text { Operational } \\
\text { resilience } \\
\text { core functions }\end{array}$} & \multicolumn{16}{|c|}{ Publications } \\
\hline & Q1 & Q2 & Q3 & Q4 & Q5 & Q6 & Q7 & Q8 & Q9 & Q10 & Q11 & Q12 & Q13 & Q14 & Q15 & Q16 \\
\hline Sense & & $\checkmark$ & & & $\checkmark$ & $\checkmark$ & $\checkmark$ & & $\checkmark$ & & $\checkmark$ & $\checkmark$ & & $\checkmark$ & $\checkmark$ & $\checkmark$ \\
\hline Build & $\checkmark$ & $\checkmark$ & $\checkmark$ & $\checkmark$ & $\checkmark$ & $\checkmark$ & $\checkmark$ & $\checkmark$ & $\checkmark$ & $\checkmark$ & $\checkmark$ & $\checkmark$ & $\checkmark$ & $\checkmark$ & $\checkmark$ & $\checkmark$ \\
\hline Re-configure & $\checkmark$ & $\checkmark$ & $\checkmark$ & $\checkmark$ & $\checkmark$ & $\checkmark$ & $\checkmark$ & $\checkmark$ & $\checkmark$ & $\checkmark$ & $\checkmark$ & $\checkmark$ & $\checkmark$ & $\checkmark$ & $\checkmark$ & $\checkmark$ \\
\hline Sustain & $\checkmark$ & $\checkmark$ & $\checkmark$ & $\checkmark$ & & & $\checkmark$ & & & & & $\checkmark$ & & $\checkmark$ & & \\
\hline Re-enhance & $\checkmark$ & $\checkmark$ & $\checkmark$ & $\checkmark$ & $\checkmark$ & $\checkmark$ & $\checkmark$ & $\checkmark$ & $\checkmark$ & $\checkmark$ & $\checkmark$ & $\checkmark$ & $\checkmark$ & $\checkmark$ & $\checkmark$ & $\checkmark$ \\
\hline
\end{tabular}

Q1: (Rice and Caniato, 2003); Q2: (Sheffi and Rice, 2005); Q3: (Allen et al., 2006); Q4: (Tang, 2006); Q5: (Craighead et al., 2007); Q6: (Waters, 2007); Q7: (Melnyk et al., 2010); Q8: (Colicchia et al., 2010); Q9: (Pettit et al., 2010); Q10: (Carvalho et al., 2011); Q11: (Jüttner and Maklan, 2011); Q12: (Ismail et al., 2011); Q13: (Manyena, 2006); Q14: (Tveiten et al., 2012); Q15: (SullivanTaylor and Branicki, 2011); Q16: (Burnard and Bhamra, 2011) 
Table 3. Synthesis relating operational resilience core functions and dynamic capabilities

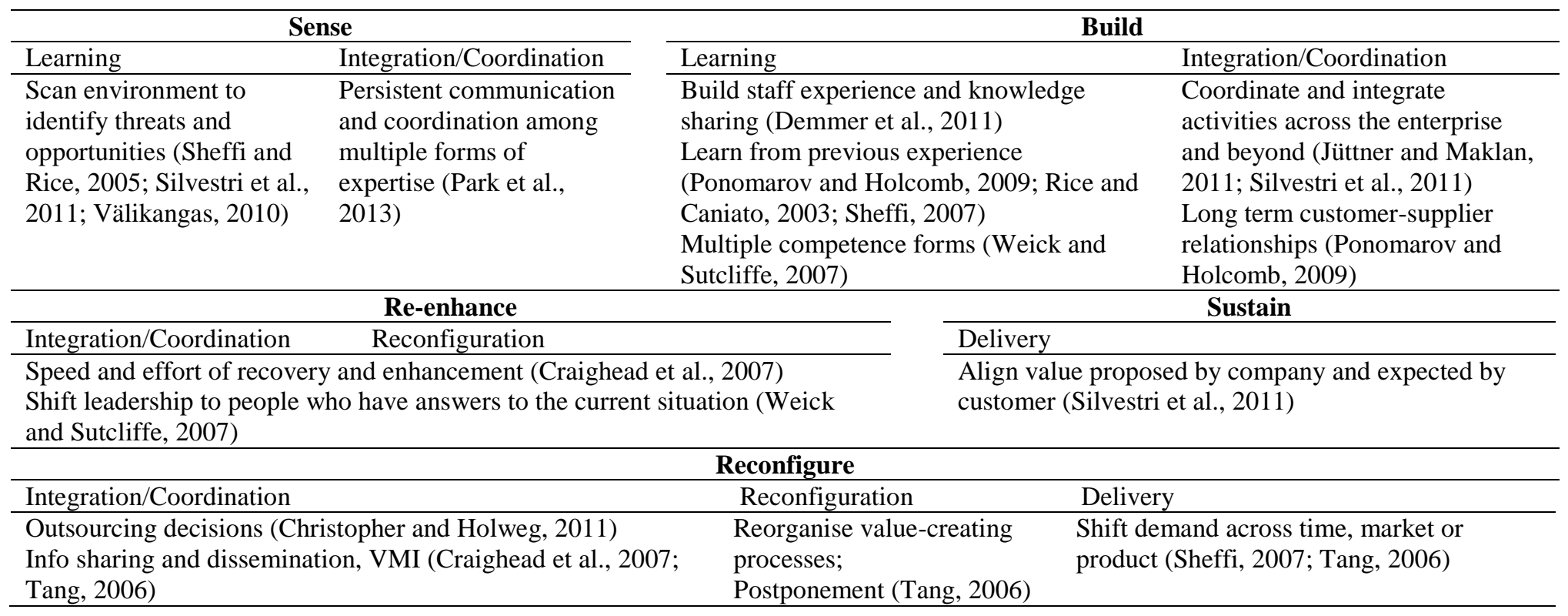




\section{Appendices}

\section{Appendix A. Some resilience definitions}

\begin{tabular}{|c|c|}
\hline Source & Definition \\
\hline $\begin{array}{l}\text { (Holling, } \\
\text { 1973) }\end{array}$ & $\begin{array}{l}\text { A measure of the persistence of systems and of their ability to absorb } \\
\text { change and disturbance and still maintain the same relationships between } \\
\text { populations or state variables }\end{array}$ \\
\hline $\begin{array}{l}\text { (Christopher } \\
\text { and Peck, } \\
\text { 2004) }\end{array}$ & $\begin{array}{l}\text { The ability of a system to return to its original state or move to a new, } \\
\text { more desirable state after being disturbed }\end{array}$ \\
\hline $\begin{array}{l}\text { (Walker et } \\
\text { al., 2004) }\end{array}$ & $\begin{array}{l}\text { The physical property of a material that can return to its original shape } \\
\text { (state or position) after deformation that does not exceed its elastic limits }\end{array}$ \\
\hline (Sheffi, 2007) & $\begin{array}{l}\text { The ability to, and the speed at which, an organisation can return to } \\
\text { 'normal' performance levels following a high-impact/ low-probability } \\
\text { event. }\end{array}$ \\
\hline $\begin{array}{l}\text { (Ponomarov } \\
\text { and Holcomb, } \\
\text { 2009) }\end{array}$ & $\begin{array}{l}\text { The adaptive capability of the supply chain to prepare for unexpected } \\
\text { events, respond to disruptions, and recover from them by maintaining } \\
\text { continuity of operations at the desired level of connectedness and control } \\
\text { over structure and function. }\end{array}$ \\
\hline $\begin{array}{l}\text { (Frost et al., } \\
\text { 2000) }\end{array}$ & $\begin{array}{l}\text { Operational resilience is the ability of a business process to adjust to or } \\
\text { recover quickly from change, disturbance or misfortune. }\end{array}$ \\
\hline $\begin{array}{l}\text { (Välikangas, } \\
\text { 2010) }\end{array}$ & $\begin{array}{l}\text { [Organisational] resilience is the capacity to change without first } \\
\text { experiencing crisis, change without a lot of accompanying trauma... } \\
\text { persist in the face of threat, not to yield, tenacity... [it is] the capacity to } \\
\text { turn threats into opportunities prior to their becoming either. }\end{array}$ \\
\hline $\begin{array}{l}\text { (McDonald, } \\
\text { 2006) }\end{array}$ & $\begin{array}{l}\text { Resilience represents the capacity (of an organisational system) to } \\
\text { anticipate and manage risk effectively, through appropriate adaptation of } \\
\text { its actions, systems and processes, so as to ensure that its core functions } \\
\text { are carried out in a stable and effective relationship with the } \\
\text { environment. }\end{array}$ \\
\hline
\end{tabular}


Appendix B. Literature search keywords

- Risk AND resilience

- (enterprise OR organisation OR operation OR “supply chain”) AND resilience

- (Vulnerability OR disruption OR uncertainty OR adaptability OR recovery OR agility OR flexibility OR mitigation OR crisis OR disaster) AND resilience

- (Resilience OR risk OR "business continuity”) AND (management OR analysis OR assessment)

\section{Appendix C. Summary of different resilience views contributing to operational resilience understanding}

\begin{tabular}{lccc}
\hline \multicolumn{1}{c}{ Perspective } & $\begin{array}{c}\text { Literature with } \\
\text { explicit } \\
\text { definitions }\end{array}$ & $\begin{array}{c}\text { Literature } \\
\text { with implicit } \\
\text { discussion }\end{array}$ & Total \\
\hline Strategic & 4 & 2 & 6 \\
Organisational & 10 & 3 & 13 \\
Supply chain & 7 & 11 & 18 \\
Business continuity & 7 & 5 & 12 \\
Infrastructure & 6 & - & 6 \\
Engineering & 2 & - & 2 \\
\hline
\end{tabular}

